\title{
A Universidade e a pesquisa histórica: apontamentos*
}

\author{
FERNANDO A. NOVAIS
}

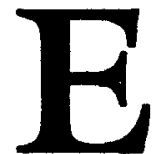

m primeiro lugar, gostaria de agradecer o convite e a oportunidade de estar hoje aqui com vocês. Farei algumas observaçóes, tendo por base antes a minha experiência de longos anos de docência universitária que propriamente um estudo direto do assunto, isto é, sobre a organização da pesquisa histórica em nossas várias universidades. A primeira observação, ponto de partida para discutir mais amplamente nosso tema nesta noite, diz respeito ao fato de que a pesquisa histórica não é exclusiva da Universidade. Quer dizer: há uma historiografia universitária e uma historiografia não-universitária, $\mathrm{e}$ isto náo só no Brasil, mas aqui $e$ alhures, ou, como diriam os franceses, en France et à l'étranger. Observando o conjunto, poder-se-ia até tentar uma tipologia. Por exemplo: há uma historiografia muito diretamente ligada às solicitaçóes do mercado, como a produçáo de biografias; biógrafos profissionais anualmente vitimam algumas personagens da História, com obras normalmente recheadas de ilustraçōes. A biografia é, como se sabe, um dos gêneros historiográficos mais difíceis. Já as teses universitárias, no mais das vezes, têm dificuldades para encontrar ediçăo, dada a inelasticidade da demanda. Pensando noutro critério, e deslocando-nos da procura para a oferta, ou antes, da circulação para a produçáo, poderíamos dizer que há livros de História produzidos individualmente, isto é, náo ligados a nenhuma instituiçăo; outros, ligados a instituiçóes năo-universitárias (como academias, institutos históricos, etc.), e finalmente a produçáo dos institutos universitários. Pelo amor de Deus, resistam à tentaçáo de ver nessa trilogia o artesanato, a manufatura e a indústria da produçáo historiográfica. Igualmente, não há que pensar que correspondam a uma historiografia fóssil, outra, tradicional, e, finalmente, a moderna. Esta última classificaçâo derivaria das características intrínsecas, mas está longe de ser rigorosa. Às vezes, o que se quer dizer com tradicionalé que, simplesmente, tradicionais são os outros; não é assim que a questão aparece na introduçáo de muitos trabalhos, em que se acerta conta de * Palestra proferida no I Encontro de Professores de História, promovido pelo Departamento de História, do Instituto
de Fílosofia e Ciências Sociais, da UFR, Rio de Janeiro. 
saída com a bibliografia, para depois não mais voltar a ela? Usualmente, contudo, por tradicional entende-se narratipo, diz-se, impropriamente, descritivo, sendo o moderno interpretativo. Ora, isso envolve o equívoco de pensar que possa haver uma narração de eventos que não seja, ao mesmo tempo, interpretação; como se fosse possível uma narraçáo em estado de graça. A verdadeira distinção é entre uma interpretação explícita e outra implícita, sendo um excelente desafio, um ótimo exercício crítico precisamente explicitara visão embutida numa obra tradicional. Mas, com isso, aquela classificaçáo vai se comprometendo.

Múltipla, variegada, a história, como domínio do saber, como regiáo do conhecimento, não só não se limita à Universidade, como é anterior a ela. Em seu sentido amplo, enquanto constituiçăo da memória social, a história é algo inerente à nossa civilizaçáo; desde a Alta Idade Média, a partir das primitivas crônicas latinas dos mosteiros antigos, vivemos por assim dizer uma necessidade civilizacional da História. Anterior à universidade, a história, como tipo de indagação, também antecede à emergência da ciência moderna; tanto que se pode estudar o impacto do nascimento das ciências, e especialmente das ciências sociais, sobre a história. Logo, a nossa disciplina tem. características específicas, corresponde a outras demandas sociais, nāo carecendo das mesmas justificaçōes. Se, por um lado, sentimos mais fortemente o peso da tradiçáo, por outro não precisamos inquietar-nos exageradamente com a pergunta com a qual Marc Bloch abre o "Métier d'historien": para que serve a história? A história $e$ simplesmente, não vai deixar de ser. Mas essas questōes nos levariam longe do nosso assunto.

Essa primeira constatação - a historiografia não se resume na produção universitária - leva-nos a pensar nas características específicas da historiografia universitária, que é o nosso tema. Às vezes, diz-se que a historiografia universitária é profissional, sendo a outra amadorística, o que tem o defeito de já envolver um juízo de valor, que nem sempre corresponde à realidade. Todo mundo sabe que boas obras de história são produzidas fora da Universidade, bem como dentro dela se produzem obras extremamente medíocres. $\mathrm{Na}$ realidade, há certas características de cunho técnico que distinguem, no conjunto (há, sempre, exceçōes), as pesquisas universitárias. Levantamento exaustivo das fontes, tratamento sistemático dos dados, indicação precisa da documentaçáo, reconhecimento bibliográfico cuidadoso, citaçóes corretas, etc. Também a preocupaçáo com problemas metodológicos. Não deve ocorrer em pesquisas da Universidade o que se observa em certos livros que a cada nova edição vão crescendo por agregação de novas fontes, antes não pesquisadas. Embora nunca se possa afirmar que um levantamento documental foi absolutamente exaustivo, há um mínimo de critério para se saber quando se pode passar à redação de um trabalho. Há também, por outro lado, um estilo de apresentaçáo, tipicamente acadêmico, das teses; do ponto de vista estético é muito ruim, nem se pode falar em estilo, antes, na ausência dele. Havia, por exemplo, o hábito da introdução teórica, isto mais em ciências sociais que em história; às vezes, a uma magnífica introdução metodológica seguia-se um mofino desempenho de 
pesquisa. Creio, por outro lado, que nos últimos anos a marca de estilo arrevesado e o emprego do jargáo têm diminuído sensivelmente, isto é, vamos progredindo.

Para situarmos a historiografia universitária em relaçáo às outras que indicamos, convém ainda compará-la com a dos institutos não-universitários. $\mathrm{E}$ aqui direi algo que vai soar como paradoxo. É que a produçáo dos institutos não-universitários me parece mais engajada, a das universidades, mais pretensamente descompromissada. Apresso-me a lembrar que engajada năo quer dizer necessariamente crítica, podendo antes ser ingênua; nem obrigatoriamente progressista, sendo às vezes conservadora. Da mesma forma, o ideal acadêmico do saber pode implicar engajamento, num outro plano. Vejamos: a produção dos Institutos Históricos - o brasileiro antes de tudo, mas também os estaduais - nos parece hoje uma produção exclusivamente erudita, ediçáo de fontes, ou comemorativa. Se observarmos retrospectivamente, porém, veremos que a criação do Instituto Histórico em 1838 insere-se no processo de consolidação do Estado Nacional; e por aí se percebe o caráter engajado dessa produção erudita: tratava-se de legitimar com o passado o presente em processo, ou dar passado à nação emergente. Daí um hipercrítico, o prof. Pedro Alcantara Figueira, dizer na sua tese ainda não publicada sobre a historiografia brasileira, que a nossa história nascente, em vez de um compromisso com a ciếncia, preferiu um pacto com o trono. Fernandes Pinheiro, membro do Instituto, anotou a traduçáo de Southey, e outro, F. A. Varnhagen, criou por assim dizer o cânon fatual de nossa história. Da mesma forma que os estudiosos do Instituto procuraram criar, como mostra o prof. Antonio Candido na sua "Formaçáo da Literatura Brasileira" , o elenco de nossa literatura; daí a publicaçáo das antologias, parnasos, florilégios e, depois, das obras completas, sobretudo o nacionalismo como critério crítico. Esse nacionalismo permitiria, ou sugeriria, um paralelo com o ISEB, em nosso século. Isto é: o ISEB estaria para a independência econômica como o Instituto esteve para a emancipação política, a ideologia nacionalista marcando ambos os discursos.

A historiografia universitária pretende ser ao mesmo tempo erudita e crítica, pelo menos como ideal; o que não significa que năo venha a ter também dimensóes ideológicas. A expressão ideológica assume então formas mais diversificadas e sofisticadas, devendo a análise que pretenda explicitá-las atravessar múltiplas mediaçóes. Não pretendemos aqui, é claro, realizar esse tipo de análise, mas apenas marcar algumas características $\mathbf{e}$ indicar algumas tendências. E começando pelo mais simples, num nível puramente quantitativo, facilmente constatável que a produção de teses e de livros de história em nossas universidades vem crescendo acentuadamente nos últimos anos. Agora, esse crescimento vegetativo-vegetativo, porque decorre da expansão do ensino superior - nāo se processou sempre com o mesmo ritmo; ao contrário, tornou-se muito mais acentuado, a partir de um determinado momento - e este momento consiste na implantação dos cursos de pós-graduação. Quer dizer: a pós-graduação marca a passagem de uma fase de produção lenta para uma fase de produçáo mais regularmente organizada. Provavelmente, havia um potencial represado, que os cursos de pós-graduaçáo serviram de canalizaçáo. Há uma lista das teses defendidas na Faculdade de 
Filosofia da Universidade de São Paulo, desde a primeira em 1939 até 1977 , quando foi feita a publicação; pode-se notar o salto, a partir do fim dos anos 60 , isto é, a partir da institucionalização do pós-graduado. Não foi apenas uma mudança quantitativa. Houve também, ao mesmo tempo, uma mudança no perfil temático das pesquisas. É notório que elas se dirigem, agora, dominantemente, quase exclusivamente, para a história do Brasil, o que é, a meu ver, uma mudança salutar, a qual tem relaçáo com a extinçáo do sistema de cátedras; neste sistema, como os menos jovens se lembram, os vários períodos è as várias fatias da história ficavam enfeudados aos respectivos catedráticos e seus assistentes. Assim, quem fosse professor de História Moderna não podia fazer História do Brasil ou da América - como se a história dessas regiōes não fosse moderna; mas é que havia as respectivas "cadeiras". Como as "cadeiras" não funcionam no pós-graduado, houve uma concentraçáo de pesquisas em história do Brasil. Na minha Universidade, dado o enorme prestígio do prof. Euripedes Simóes de Paula, houve uma época em que as pesquisas de historia antiga e medieval chegaram a predominar - o que se aproxima do absurdo. Veja-se bem: não estou querendo dizer que só devamos pesquisar história de nosso país, o que seria uma estultícia. Acho que as pesquisas devem ser o mais diversificadas possível. É mesmo um indício de desenvolvimento e de maturidade essa abertura para os vários momentos da história. Agora, é também certo que ainda não temos o volume de recursos para essa ampliação. As pesquisas de história antiga e medieval envolvem enormes dificuldades de material, quase sempre com estágio no Exterior. A náo ser que se queira multiplicar compilaçóes. Ora, dada a escassez de recursos, esse tipo de trabalho não deve de maneira nenhuma ser abandonado, mas dosado; isto é: não deve ser predominante. Deve estar presente, mas não ser predominante. Em suma, creio que nos últimos anos a situaçăo tende a se normalizar.

As vezes, diz-se que a historiografia universitária é profissional, sendo a outra amadoristica, a que tem o defeito de já envolver um jufzo de valor, que nem sempre corresponde à realidade.
Houve, portanto, no último decênio, um crescimento e uma diversificação na produção universitária brasileira de história. Examinemos um pouco mais de perto essa diversificaçáo. Examinada no conjunto, a produção parece envolver um deslocamento de interesse no tempo - período colonial para o republicano - e na área - da história econômica para a história política. Todos os que orientam pós-graduandos em História sabem como é difícil atraí-los para temas de história do período colonial; a preferência vai amplamente para o período republicano, e mesmo para os períodos mais recentes da República. Ora, há dez ou quinze anos era nitidamente o contrário que se dava. Igualmente, um pouco mais atrás no tempo, a preferência ia para história econômica; hoje, para história política, ou história das ideologias, que é também história política de certa forma. O prof. Amaral Lapa, no seu livro "História em Questáo" (conjunto de estudos de historiografia brasileira), já aponta essas tendências, inclusive com tabelas e gráficos; seus dados vão até 1973, mas estamos certos de que a tendência de lá para cá acentuou-se. Se meditarmos um pouco sobre essas constataçōes, veremos como esses deslocamentos temáticos expressam as pulsaçōes mais significativas de nossa história recente. O golpe de 64 e os desdobramentos do regime militar-autoritário levaram a um como que 
enxame de consciência da intelectualidade brasileira e dos historiadores no seu bojo. Daí as constantes reavaliaçōes, as variaçōes dos focos de preocupação. Por exemplo, o reestudo do significado do tenentismo. Daí a preocupaçáo com a história mais recente na sua dimensão política. Há outros aspectos que também podem ser relacionados com a nossa evoluçáo política mais recente. Acentuou-se o interesse do centro hegemônico, isto é, dos Estados Unidos; avolumando-se, em conseqüência, os estudos dos brazilianistsque, hoje, configuram quase um alude, que nos vai afogando. Esta imagem, proposital, é para indicar a reação mais comum que nos provoca a "invasão" americana. Mas é claro que temos que superar essa reação emocional; os estudos norte-americanos sobre o Brasil - de resto, sobre o mundo todo são um dado de realidade com o qual temos que nos defrontar madura e racionalmente. Isto é: náo podemos cair nem na xenofobia (pretender ignorar, ou exorcizar o "brasilianismo"), nem no provincianismo que também ocorre (entrar em êxtase diante da maravilha); o que temos é que assimilar criticamente a produção dos brasilianistas, tornando-a instrumento de reflexão. Mas o brasilianismo norte-americano teve, a meu ver, certos desdobramentos ou antes subprodutos em nosso meio, que vale lembrar. O deslocamento de interesse para a história da República, parece-me que, pelo menos em parte, se deve a uma reação em face das pesquisas dos brasilianistas que se dirigiam dominantemente para o período mais recente de nossa história. Assim, ia-se configurando uma situação em que os brasileiros estudavam a colônia e os americanos, a República. Contra essa alienafão reagiram vários de nossos historiadores, e hoje já contamos com um número razoável de republicanistas. Vejam que os caminhos da pesquisa são muitas vezes curiosos e surpreendentes.

Ligada a essa diversificação e a esses deslocamentos temáticos, aparece uma outra tendência de nossa atual historiografia universitária. Refiro-me à multiplicação dos estudos de historiografia, isto é, de história da história. Há algum tempo, entre nós, José Honório Rodrigues era praticamente o único a se dedicar a esse gênero de estudos; e ele continua se dedicando intensamente (em 1979, publicou o primeiro volume da "História da História do Brasil", que envolverá pelo menos mais dois tomos), mas já agora com vários outros acompanhantes. Seu próprio trabalho já foi objeto de uma tese de Raquel Glezer, da USP. Se acompanharmos, por exemplo, os anais dos sucessivos simpósios de nossa Associação Nacional dos Professores Universitários de História, fica claro como o tema, pouco tratado nos primeiros, vai-se avolumando nos últimos anos. Nos encontros regionais quase sempre há mesas-redondas, debates, balanços de historiografia. No mais das vezes, tomam-se certos temas, ou certos períodos, para se proceder a uma avaliação. Já as teses têm se voltado para o estudo de autores, como Varnhagen (Nilo Odália), J. F. Lisboa (Maria de Lourdes Janotti), Southey (Maria Odila Silva Dias), Capistrano de Abreu (Jayro G. de Melo). Também aqui, mais uma vez, expressa-se esse exame de consciência a que a intelligentsia brasileira vem sendo levada; além de que, já o simples crescimento e diversificaçáo tende a sugerir essa espécie de introspecçáo que săo os estudos de história da história.

Se compararmos, agora, nossa historiografia universitária com a de outros países, creio que ressalta uma característica que a aproxima da 
dos países latino-americanos e a afasta da dos países centrais (Europa e Estados Unidos). Trata-se de um maior entrosamento, ou, se quiserem, melhor conveniência com as outras ciências sociais; este parece ser um traço da historiografia universitária latino-americana. Na norte-americana, bem como na européia, a separação é mais nítida, assim como a especializaçáo dos pesquisadores é mais acentuada. E não é um fenômeno específico dos historiadores, mas dos cientistas sociais em geral; vejam como nossos sociólogos, economistas, antropólogos interessam-se por história. Algumas obras muito importantes de nossa historiografia foram escritas por economistas e sociólogos. Nos Estados Unidos, um autor como Wallerstein sociólogo, autor de obras fundamentais de história - faz figura de exceção. Há, entre nós, uma historicização das ciências sociais, sem como maior teorização da história. $\mathrm{E}$ isto se liga, como é fácil perceber à maior presença do marxismo em nosso meio intelectual. Entre nós o marxismo não é - como no chamado Primeiro Mundo - uma doutrina entre outras; trata-se, por assim dizer, do referencial do debate das idéias. Náo estou querendo dizer que todos, nem que a maioria, aqui, sejam marxistas. Nem que o marxismo que se faz aqui seja melhor que o dos países centrais. Há bons e medíocres trabalhos, cá e lá. A diferença que estou querendo marcar é de atitude; o marxismo está sempre presente em nosso horizonte intelectual, forma, por assim dizer, o caldo de cultura - o que não ocorre nos Estados Unidos e na Europa.

Esta última característica (maior integração com as ciências sociais, menor grau de especializaçáo) parece-nos claramente uma vantagem a ser preservada. Em contraposição, a nossa historiografia atual, quando cotejada com a dos centros mais avançados (por exemplo, com a historiografịa francesa), não apresenta a mesma riqueza temática. A abertura de novos temas (novas sendas na floresta da realidade, como diria Paul Veyne), sobretudo no campo da história das mentalidades, da sensibilidade, do cotidiano, que marcam o perfil da historiografia francesa atual, não se manifesta em nossa atual produçáo de modo relevante. Basta pensar nos estudos sobre história da loucura, das atitudes em face da morte, da criança e da família, do medo e do sentimento de culpa, das práticas mágicas e da feitiçaria, da sexualidade, para sentirmos nosso distanciamento. Isto se prende, talvez, à tendência que indiquei de início de nos concentrarmos mais em nossa própria história. Tenho a impressão que as gerações mais novas lêem menos a historiografia estrangeira, sentindo menos seus influxos. Note-se que não creio que se deva partir para a imitação temática, e começar a procurar aqui os mesmos temas. O que um acompanhamento da bibliografia mais avançada deve proporcionar é uma atitude mais criativa; isto é: procurarmos a abertura de novos temas na nossa realidade.

Estas observaçóes procuram, como vocês estáo notando, dar uma visão equilibrada de nossa atual historiografia, evitando o otimismo comemorativo e o negativismo doentio. Na realidade, creio que podemos dizer que a historiografia universitária brasileira tem progredido significativamente, mas está ainda aquém das suas potencialidades. $E$ isto - esta diferença entre a realidade $e$ a possibilidade - deve-se não somente à falta de recursos, de apoio, 
embora essa seja a razão principal; deve-se também a problemas de organização dos estudos e pesquisas, bem como à nossa baixa produtividade. E nesse "nós" é claro que eu me incluo; temos hábitos intelectuais herdados da tradiçáo que nos levam a viver as atividades do espírito mais como fruiçáo que como produção - todos gostamos mais de ler que de escrever, não é assim? A medida, porém, que avança a modernizaçăo, isto é, que o capitalismo se consolida, vamos nos enquadrando, e acabaremos todos altamente competitivos como nos grandes centros...

Falando, portanto, das limitaçóes, creio que devamos lembrar, em primeiro lugar, a escassez das obras de apoio, isto é, os instrumentos de trabalho: guias de arquivos, repertórios documentais $e$ bibliográficos, etc. Aqui, também, tem havido progressos, mas ainda insuficientes; todos conhecem as publicaçóes que têm surgido nos últimos anos, e que muito têm ajudado nas pesquisas, mas há ainda grandes lacunas. Só agora, por exemplo, começamos a ter listas das teses defendidas (o chamado "banco" de teses). Igualmente, nossos arquivos têm passado por um processo de modernizaçáo bem marcado, mas no conjunto ainda deixam a desejar. $O$ de Sáo Paulo, que é muito rico, não tem sede própria. Muita documentaçăo tem se perdido por falta de uma política nacional definida de arquivamento. Mas, nesse capítulo dos instrumentos de trabalho, a grande catástrofe são mesmo as bibliotecas. Aqui, os progressos, se existem, sáo tão ridículos que náo dá para perceber. Dá-me um frio na espinha quando ouço dizer que a biblioteca de história da USP é a melhor do país, em termos de biblioteca departamental. Eu a conheço bem, de fato tem um grande acervo (longe do que deveria ser), mas há muitíssimos anos que não se consegue um mínimo de organização para funcionar razoavelmente. E um problema que se arrasta. Conheço vários campi modernos de universidades federais que possuem excelentes prédios para bibliotecas centrais - mas sem livros.

A Universidade brasileira não logrou ainda, por outro lado, encontrar uma fórmula equilibrada para a organização da pós-graduação. $\mathrm{Na}$ USP, o pós-graduado dá mais ênfase à pesquisa que a cursos e está centrado desde o início no orientador. Há vantagens e desvantagens. Limita o número de vagas; como, em história, até há pouco, a USP era o único doutorado (agora há também o do Paraná, em Curitiba) - o resultado tem sido um autêntico bloqueio. Já o esquema das universidades federais permite aliviar a questáo de vagas. Como os pós-graduandos não entram diretamente com orientador, e fazem mais cursos, enquanto estão fazendo os cursos não têm orientador. Noutros termos: o número de pós-graduandos é maior que o de orientandos, enquando na USP é o mesmo. Se pénsarmos, agora, que até há pouco a USP era o único doutorado de história, vế-se bem a distorçáo; os pesquisadores se mestravam nos vários cursos, e iam procurar doutorado na USP, onde não havia vagas. Isto em parte continua. $O$ problema é conhecido, óbvio, mas não se resolve, dada a imutabilidade burocrática. Uma vez instalado, mudar é dificílimo. Nem o Conselho Federal de Educaşáo (CFE) permite ampliar as vagas por orientador, nem a USP muda o sistema de ingresso - embora todos digam que reconhecem o problema. Do ponto de vista das pesquisas, o sistema da USP, se tem maior flexibilidade (permitindo todo tipo de pesquisa), 
perde em coordenação; no outro esquema (das federais em geral, e também, em São Paulo, da Unicamp), se ganha em coordenação (dada a programaçáo), perde em flexibilidade. Os programas, por seu turno, facilitam a obtenção de recursos, pois as agências financiadoras de pesquisas e patrocinadoras de bolsas dão preferência a trabalhos enquadrados em conjuntos programados, que é como se recomenda em ciências exatas.

O encaminhamento e resoluçăo desses problemas depende de mudanças que transcendem a corporação dos historiadores, mas também de nossa capacidade de mobilizaçáo e pressáo. Ninguém vai abrir espaço de graça para os outros. Temos que reivindicar firme e permanentemente o aumento dos recursos, promover debates e propor mudanças no sistema de organização dos programas de pós-graduaçăo, como este que aqui se promove.

Fernando A. Novais, historiador e professor de História da USP e UNICAMP e membro da área de concentração de História das Ideologias e Mentalidades do IEA. 